\title{
O CRISTÃO-NOVO LETRADO COMO SUJEITO COLONIAL NO BRASIL E NO MÉXICO SEISCENTISTA: QUESTÕES HISTORIOGRÁFICAS E CANÔNICAS ${ }^{1}$
}

\author{
POR \\ Lúcia Helena Costigan \\ The Ohio State University
}

Bento Teixeira (1561-1600) e Luis de Carvajal, el Mozo (1567-1596) são protótipos de conversos ou cristãos-novos letrados que na colônia sofreram os reveses da Inquisição por descenderem de hebreus e por serem acusados de continuar seguindo a crença e filosofia de seus ancestrais. E para que melhor se possa entender o drama existencial do criptojudeu, como ser dividido entre Cristo e Moisés, e a problemática do cristão-novo nas dependências portuguesa e espanhola da América é necessário remontar ao contexto peninsular que o gerou.

Apesar das perseguições esporádicas sofridas na Península Ibérica pelos povos hebreus, que a partir da diáspora haviam emigrado para a Mesopotâmia e, posteriormente, para a Espanha e Portugal, desfrutaram de liberdade e de prosperidade nos reinos dominados pelos mouros. A partir, porém, das Cruzadas e, particularmente, de 1474, ano em que os reis católicos Isabel e Fernando subiram ao poder e empreenderam a fase final da unificação dos reinos, mudanças radicais ocorreram na vida dos sefardins ou judeus peninsulares. $O$ cristianismo compulsório imposto pelos reis católicos e a instituição do Tribunal do Santo Ofício em 1478 provocou grande transtorno na vida dos adeptos da lei mosaica. A partir de então, os judeus espanhóis submetidos ao batismo passaram a ser identificados como conversos ou marranos.

Uma vez que parte dos seguidores da crença mosaica se opôs à conversão forçada, os reis ordenaram a expulsão dos rebeldes, tentando, de tal forma, erradicar do território espanhol recém unificado os elementos considerados heréticos e ameaçadores da fé católica. Em decorrência de tal impasse, em 1492 milhares de judeus expulsos da Espanha, buscaram refúgio nas vizinhas terras portuguesas. Como documenta Damião de Góis, cronista oficial da corte portuguesa em sua obra Crónica do felicíssimo rei dom Manuel (1566-1567), durante os últimos anos do reinado de Dom João II os imigrantes da raça hebréia sofreram condições de escravagismo. Porém, ao subir ao trono em 1495, Dom Manuel I, o Venturoso, favoreceu os seguidores da lei mosaica resgatando-os da condição degradante em que se

\footnotetext{
${ }^{1}$ Gostaria de registrar aqui o meu agradecimento à Ohio State University e à Memorial Foundation for Jewish Culture por terem possibilitado, através de apoio financeiro, que eu pesquisasse os processos inquisitoriais de Bento Teixeira e de Luis de Carvajal, el Mozo, na Torre do Tombo, em Lisboa, e no Archivo General de la Nación, na cidade do México.
} 
encontravam, porque via na experiência milenar e no dinamismo dos judeus fator potencial para o crescimento econômico da nação lusitana. Desafortunadamente, a situação de privilégio e de liberdade concedida aos israelitas imigrados para Portugal pouco durou. Começou a se deteriorar quando o Venturoso, ao contrair matrimônio com dona Maria, filha dos reis católicos, comprometeu-se a expulsar das terras portuguesas os infiéis mouros e judeus. Pressionado pelas exigências dos monarcas espanhóis e pelo desejo de ver prosperar Portugal com a contribuição dos talentos dos judeus, em vez de tomar medidas enérgicas para expulsá-los do reino lusitano, Dom Manuel preferiu vedar-lhes o êxodo e buscar incorporá-los à sociedade e à igreja através de medidas arbitrárias como a do batismo forçado, o sequestro dos filhos menores de catorze anos das famílias judias, os quais foram colocados sub a tutela de católicos, e o decreto estabelecendo que no decorrer de trinta anos os judeus submetidos ao batismo compulsório não seriam inquiridos a respeito da crença que seguiam. Para garantir aos judeus borrifados com água batismal, a partir de então, identificados como cristãos-novos, que eles não seriam perseguidos, o Venturoso proibiu a presença da Inquisição nas terras portuguesas durante o seu reinado. ${ }^{2}$

Teoreticamente, através do batismo forçado, o judeu, como pessoa jurídica, étnica e religiosa deixou de existir, nos impérios espanhol e português. Na prática, porém, 0 antisemitismo se aguçou porque o converso ou cristão novo, tanto na Espanha quanto em Portugal, era tido como suspeito de continuar sendo judeu. De 1497, ano da expulsão dos judeus do reino lusitano, até 1774 , data em que a diferença entre cristão-novos e cristãosvelhos foi abolida de uma vez por todas da sociedade portuguesa as discriminações contra os cristäos-novos se aguçaram ou se atenuaram segundo a filosofia econômico-política dos reis que se revezavam no poder.

Conforme postulam José Gonçalves Salvador, Antônio José Saraiva e Anita Novinsky, entre os historiadores do tema, as perseguições e discriminações contra conversos de linhagem hebréia persistiram e recrudesceram. Possivelmente isso ocorreu porque na mentalidade hierárquica e excludente da época, o mecanismo da conversão e do batismo forçados criou o cristão-novo como bode expiatório, ou seja, como inferior ao cristão tradicional ou cristão velho, o qual era tido como portador de valores morais, sociais e étnicos superiores. ${ }^{3}$ Em parte, e como bem aclara A. Novinsky em sua obra Cristãos novos na Bahia, a condição de subalternidade e de ser dividido experimentada pelo cristãonovo o levou a optar pelo cripto-judaísmo, como forma de afirmação individual.

${ }^{2}$ Antônio José Saraiva, Inquisiçäo e cristãos-novos (Porto: Editorial Inova, 1969), compara as medidas adotadas pelso reis católicos com as tomadas pelo rei Dom Manuel para expulsar de suas terrras os judeus e conclui que em Portugal "tudo foi feito para dificultar o embarque dos judeus que insistiam em partir" (39). Tal asserção se explica com o fato de ter o rei português fechado quase todos os portos e de ter dado aos hebreus um prazo de mais de dez meses para a partida, enquanto que Isabel e Fernando, num território muito mais extenso e com população muito maior, apenas lhes concederam quatro meses.

${ }^{3}$ Em sua obra Cristãos-novos, jesuitas e Inquisição (São Paulo: Livraria Pioneira Editora/EDUSP, 1969) José Gonçalves Salvador afirma que a partir do batismo compulsório "os cristãos-velhos passaram à categoria de raça eleita e único povo abençoado" (1). De acordo com A. J. Saraiva, o judeu não era a causa do anti-semitismo, "mas o seu pretexto ... [porque] o hábito generalizado de odiar e humilhar o Judeu faz parte de um sistema social de tensóes afectivas que o simples facto de 
Tomando como exemplo o caso de Bento Teixeira e de Luis de Carvajal, el Mozo, este trabalho visa delinear a experiência do converso sefardita emigrado para o Novo Mundo, especialmente a partir de dois momentos distintos na história colonial iberoamericana. De 1536, ano da chegada da Inquisição nas terras lusitanas, e de 1580, ano da anexação de Portugal e de suas colônias ao império espanhol.

É possível admitir que a emigração de grupos cristãos-novos para o Novo Mundo se intensificou a partir da morte de Dom Manuel I e da subida ao trono do seu filho e sucessor, Dom João III, em 1521. Foi com a ocorrência de tais fatos que a situação dos conversos portugueses se deteriorou. A 23 de maio de 1536 foi criada a Inquisição em Portugal por concessão do Papa Paulo III, obtida com a interferência de Carlos V, cunhado de Dom João III. Talvez para escapar da perseguição inquisitorial que começava escrutinar a crença dos portugueses de linhagem hebréia, milhares deles, apesar de oficialmente proibidos de emigrar para o Novo Mundo, lograram chegar ao Brasil. Alguns dos emigrantes hebreus seguiram para as colônias espanholas, enquanto que a maioria permaneceu nas terras portuguesas da América, dedicando-se ali à colonização das capitanias do Norte e do Sul. Data de 1534 a chegada de Duarte Coelho, donatário que incentivou a imigração de milhares de cristãos-novos portugueses que na capitania do Pernambuco desenvolveram a tecnologia dos engenhos açucareiros. Conforme esclarecem Arnold Wiznitzer e J. Gonçalves Salvador, ${ }^{4}$ os cristãos-novos e judeus dedicaram-se à exploração da madeira pau-brasil, à comercialização de escravos e ao cultivo da cana-de-açúcar. Uma vez que as grandes minas de ouro do Brasil ainda não haviam sido descobertas, a comercialização da cana-deaçúcar se constitui na mola propulsora da economia e do desenvolvimento da colônia portuguesa da América nos séculos XVI e XVII.

A distância da metrópole permitiu relativa liberdade espiritual e espargimento mundano aos cristãos-novos, judeus ou realmente convertidos ao catolicismo, que buscavam nas terras americanas melhores condições de vida. Nas regiões remotas do Novo Mundo, como na capitania do Pernambuco, no Brasil, e no Novo Reino de Leão, distante da capital do vice-reinado da Nova Espanha, foi onde o aspecto mundano parece ter sido mais aguçado.

$\mathrm{O}$ fato de que naquelas regiões nordestinas marginais e distanciadas da corte existia relativa liberdade religiosa e tendência ao espírito mundano, pode ser comprovado através da descrição dos missionários Fernão Cardim e Vicente de Santa Maria. Em 1584, ao documentar suas impressões do ambiente social no Pernambuco, Cardim deixou claro que os habitantes da vila pernambucana de Olinda exibiam mais luxo e riqueza do que os de Lisboa, capital portuguesa. $\mathrm{O}$ aspecto barroco do carpe diem, ou seja, da tendência para o

conversão em massa dos Hebreus portugueses não podia por si só abolir" (47). Anita Novinsky reinforça a tese de ter sido o cristão-novo um bode expiatório do sistema social que o criou, quando observa em sua obra Cristãos-novos na Bahia (São Paulo: Editora Perspectiva/EDUSP, 1972) "que muitas vezes os cristãos-novos confessavam sua culpa de judaísmo, sendo completamente inocentes" e "que os Processos oferecem o perigo de serem do fabrico da Inquisição, que queria justificar a existência do Tribunal" (141).

${ }^{4}$ Vejam-se Arnold Wiznitzer, Os judeus no Brasil colonial (São Paulo: Pioneira/EDUSP, 1966) e J. Gonçalves Salvador, Os cristãos-novos: povoamento e conquista do solo brasileiro, 1530-1680 (São Paulo:Pioneira/EDUSP, 1976). 
efêmero e o mundano se evidencia através da vaidade e da aparente falta de fé cristã das mulheres locais, como se pode observar através das palavras de Cardim: "As mulheres são muito senhoras, e não muito devotas, nem frequentam as missas, pregações, confissões, etc. Vestem-se ... de toda a sorte de veludos, damascos e outras sedas, e nisto têm grandes excessos" (154). ${ }^{5}$ Semelhante impressão de mundanidade barroca emerge na seguinte descrição do Novo Reino de Leão feita pelo frei Vicente de Santa Maria:

Parece que el Nuevo Reino de León era el estómago donde se diregían las malígnas especies de sedición cuya acrimonia trancendía al cuerpo de aquellas fronteras. ${ }^{6}$

No entanto, o ambiente libertino naquelas regiões marginais e remotas dos impérios peninsulares começou a mudar a partir das medidas tomadas pelo monarca espanhol Filipe II que, ao invadir e anexar Portugal e suas colônias ao reino espanhol, em 1580, tomou medidas no sentido de melhor controlar o seu vasto império. A perseguição dos descendentes de judeus emigrados para o Brasil e para os domínios espanhóis da América se intensificou com a pressão da política ideológica do segundo herdeiro dos Habsburgo espanhóis. No vice reinado da Nova Espanha o Tribunal do Santo Oficio já tinha sido estabelecido por Filipe II desde 1571. No Brasil, apesar da oposição dos governadores gerais e donatários de capitanias, o Tribunal do Santo Ofício marcou sua presença de forma indireta a partir de 1591 através do visitador Heitor Furtado de Mendonça, eclesiástico da confiança do monarca espanhol, enviado ao Brasil como representante da Inquisição. Foi a partir do Concílio de Trento (1545-1563) e da Contra-Reforma e, mais especificamente, com o breve Dedum Charissimi proibindo descendentes de hebreus de ingressar nas ordens religiosas e com o estatuto de puritate sanguinis vedando-lhes o exercício da profissão de boticário e de médico, que o converso viu agudizar o drama da sua identidade cristã-nova. E é justamente nos contextos coloniais da capitania do Pernambuco e do Novo Reino de Leão onde vamos encontrar, no fim do século XVI, Bento Teixeira e Luís de Carvajal, el Mozo. Ambos eram letrados descendentes de cristãos-novos portugueses acusados de corromper o Novo Mundo com a prática do judaísmo.

O nome de Bento Teixeira entrou para as páginas inquisitoriais a partir das confissões e denúncias ouvidas na Bahia e registradas por Heitor Furtado de Mendonça durante sua primeira "visitação do Santo às partes do Brasil". Foi, porém, durante a visitação do Pernambuco, que o cristão-novo emigrado para o Brasil na idade de cinco anos se apresentou aos oficiais do Santo Ofício. Isto se deu a 21 de janeiro de 1594, data em que Bento Teixeira entregou ao visitador uma confissão lavrada a punho. Apesar de sua veemente defesa, através de discurso confessional escrito, Bento Teixeira foi apreendido no dia 29 de agosto de 1595 e no ano seguinte enviado para o cárcere da Inquisição de Lisboa.

Por sua vez, Luis de Carvajal, el Mozo, converso letrado que na adolescência havia emigrado para o vice-reinado da Nova Espanha, tornou-se vítima da Inquisição mexicana

\footnotetext{
${ }^{5}$ Fernão Cardim, Tratados da terra e da gente do Brasil (1881; Belo Horizonte: Editora Itatiaia/São Paulo, 1980) 164.

"Veja Reseña geográfica y estadistica, "Estado de Nuevo León" (Paris/México: Librería de la Viúda de C. Bouret, 1908) 5.
} 
no ano de 1589 , data em que foi preso sob acusação de judaizante. O direto envolvimento de Luis de Carvajal com o Tribunal do Santo Ofício compreende duas etapas e dois processos distintos. O primeiro, iniciado com a prisão do réu no dia 9 de maio de 1589 , terminou no dia 8 de novembro do mesmo ano. Durante o auto de fé realizado na capital do vicereinado no dia 8 de novembro de 1589 , Carvajal mostrando aparentemente arrependimento por ter abraçado a crença mosaica, publicamente abjurou o judaísmo, reconciliando-se com a Igreja católica. Apesar de sua aparente reconciliação, Carvajal continuou criptojudeu, fingindo publicamente ser cristão, enquanto que ocultamente continuava adepto do judaísmo. Acusado por um de seus confrades, Luís foi novamente incarcerado pela Inquisição no dia 1 de fevereiro de 1596. Desta vez pagaria com a vida o crime de ter sido considerado herético, relapso e apóstata. No dia 8 de dezembro de 1596 Carvajal foi morto e relaxado no grande auto-de-fé que também sentenciou com a morte outros membros de sua família. Saíram reconciliadas no mesmo auto-de-fé quarenta e cinco pessoas acusadas de judaizantes, a maioria das quais descendentes de cristãos-novos portugueses. Coincidentalmente, foi no mesmo ano de 1596, quando a Inquisição mexicana apertava o cerco contra os descendentes de cristãos-novos portugueses, que Bento Teixeira seguiu para Lisboa como prisioneiro do Santo Ofício. Em Lisboa Bento Teixeira participou no auto-da-fé de 31 de janeiro de 1599, mostrando-se arrependido de seus desvios e abjurando o judaísmo. Como recompensa, em lugar da pena de morte, recebeu o sambenito, hábito penitencial e a prisão residencial perpétuos a serem cumpridos em Portugal. Apesar de ter se livrado da morte na fogueira, o letrado do Pernambuco pereceu de tuberculose em julho de 1600 no hospital da Inquisição de Lisboa.

Para escapar da perseguição inquisitorial, tanto Bento Teixeira quanto Luis de Carvajal utilizaram seus talentos de letrados, talvez buscando através da retórica ganhar a simpatia dos seus verdugos e, ao mesmo tempo, sutilmente, protestar contra a política religiosa discriminatória vigente nos domínios de Filipe II. Através dos discursos confessionais orais e escritos dos dois penitentes é possível perceber o uso da retórica do letrado criptojudeu, que se manifesta algumas vezes de tom bajulatório, talvez para angariar o perdão dos inquisidores, e outras vezes em tom crítico e de maneira sutil, para protestar as injustiças contra os descendentes de hebreus.

A confissão escrita por Bento Teixeira e incluída no seu processo inquisitorial consiste num documento onde a retórica do converso letrado se manifesta através da ação ou iniciativa de se defender perante o Santo Ofício através de uma confissão autobiográfica. O documento como confissão escrita, foge aos padrões tradicionais da Inquisição. Isto se justifica com a explicação de que o Manual dos Inquisidores, pautado no Directorium Inquisitorium de Nicolau Emérico (1320-1399) estipulava que o processo deveria "ser tanto quanto possível encurtado ... rejeitando toda e qualquer apelação" e que as confissões dos denunciados deveriam ser feitas oralmente seguindo um questionário previamente preparado pelos inquisidores nos moldes dos padrões do Manual. O fato de que a Bento Teixeira lhe fosse permitido apelar ao visitador do Santo Oficio por meio de um documento escrito foge do modelo típico de confissão inquisitorial. A meu ver, o ato de se expressar através da escrita possibilitou-lhe o uso da retórica para ganhar a simpatia dos inquisidores.

\footnotetext{
${ }^{7}$ Nicolau Emérico, O manual dos inquisidores (1578; Lisboa: Ediçð̃es Afrodite, 1972) 11.
} 
Bento Teixeira inicia sua confissão apelando pela "misericórdia e brandura de Deus e do Tribunal" e admitindo que "como humano e pecador tivera cometido gravíssimas culpas". ${ }^{8}$ Logo em seguida, e ao longo de sua confissão, vai, gradativamente, inocentandose do crime de ser judeu. Afirma, repetidas vezes, que sempre vivera "católica e exemplarmente, sem nunca ser acoimador de maus cristãos". Transfere a causa de seus pecados para terceiros ou para forças além do seu controle, como se vê na passagem seguinte onde ele explica que por ser jovem e inocente, tornara-se vítima da mulher libidinosa que o traíra e que o levara ao uxoricídio:

E como o caminho do mancebo na primavera de sua mocidade será dificultado ... E pela ... experiência que então não tinha deixei de acabar meus estudos e fui ter à capitania dos Ilhéus, e ali preso do lascivo amor duma Felipa Raposa, filha de André Gavião, me casei com ela, sendo a dita tão nobre na geração, como nos seus próprios vícios: a qual segundo tenha alcançado foi a fonte donde se originaram meus trabalhos, e a prisão que de presente padeço.

Dirigindo a atenção do leitor para o fato de que "os gravíssimos pecados" por ele admitidos no início da sua confissão consistiam no fato de ter assassinado a esposa adúltera, Bento Teixeira busca esvaziar do seu discurso a culpa de ser judeu, fato que na época era visto como crime muito mais grave do que uxoricídio. Na busca de isentar-se de culpas, o letrado cristão-novo tenta persuadir os inquisidores de que não deviam dar ouvidos aos que o culpavam de ser judeu, porque todos os que o acusavam faziam-no por inveja e por terem sido "mártires diabólicos" da volúpia de Felipa Raposa, a quem Bento Teixeira compara com a "Hydra de Sete Cabeças". Talvez para garantir a simpatia dos inquisidores, o confessante se faz de vítima, justificando que matara sua mulher para defender sua honra: "e eu vendo que o negócio era público, e que minha honra andava empenhada por casas alheias, e só fazia inventário de minha vida foi necessário ... matá-la".

No caso do processo de Luis de Carvajal, talvez por existir no México um Tribunal do Santo Ofício, os inquisidores seguiram mais fielmente as instruções do Manual, pois não deram ao letrado da Nova Espanha a oportunidade de apelar por meio de confissão escrita. No entanto, isto não impediu que Carvajal escrevesse em frutas e em pedaços de papel mensagens de esperança na vida eterna e de protesto contra as injustiças aos judeus. Quase tudo o que o cristão-novo da Nova Espanha redigiu foi interceptado e usado pelos inquisidores para questionar e para incriminar o réu, seus familiares e aproximadamente cento e vinte indivíduos que supostamente faziam parte de uma ativa comunidade de criptojudeus na capital do vice-reinado da Nova Espanha.

Detendo mais pormenorizadamente nas manifestações escritas por ambos penitentes, percebe-se, através das cartas e do testamento de Carvajal e do poema Prosopopéia e da confissão de Bento Teixeira, o intento de persuadir os inquisidores de que era erro persegui-

\footnotetext{
${ }^{8}$ Todas as passagens da confissão de Bento Teixeira citadas neste texto foram extraídas do manuscrito do "Processo 5.026 da Inquisição de Lisboa" cujo original se encontra no Arquivo Nacional da Torre do Tombo em Lisboa. As citações não apresentam referência às pàginas em que se encontram porque no Processo 5.026 as mesmas não se encontram devidamente enumeradas.
} 
los. Na confissão de Bento Teixeira encontram-se frases que parecem ter sido escritas com o propósito de esclarecer que o fato dele ser cristão-novo não deveria ser considerado crime, pois fora Deus quem o fizera descender de hebreus. Tal argumentação se expressa através das seguintes palavras dirigidas aos inquisidores: "Se antes que eu nascesse me perguntassem qual queria: ser filho de cristão-velho ... eu por minha eleição tornara ser filho de cristão-novo ... se Deus nosso Senhor foi servido que meu pai fosse cristão-novo ... que culpa tenho eu?" O confessante se dirige aos membros do Tribunal do Santo Oficio em termos respeitosos, talvez buscando receber dos mesmos "misericórdia e brandura". De maneira semelhante, Luis de Carvajal tentou conquistar a simpatia dos inquisidores. Em suas Memórias, expressando-se através do personagem Joseph Lumbroso, Luis de Carvajal relata haver prestado serviço ao irmão do inquisidor, para em seguida pedir-lhe cartas que lhe autorizassem arrecadar fundos para obter para si e toda sua família perdão inquisitorial. O cristão-novo da Nova Espanha, além de se mostrar orgulhoso de ser judeu, questiona os dogmas do cristianismo ao argumentar, no "Testamento" que ele escreveu e audaciosamente entregou aos inquisidores, que: "lo que dicen los cristianos que los preceptos ceremoniales y judiciales son muertos y que ya se expiraron es contra uno de sus mismos evangelios". 9 Como se pode observar através das passagens citadas, tanto nas "Memórias" de Carvajal quanto no poema de Bento Teixeira se percebe a mensagem do cripto-judeu letrado que se manifesta, ora sutil ora claramente, como resistência ao antisemitismo e como apologia ao judaísmo.

As "Memórias", escritas após Carvajal haver sido sambenitado e renunciado publicamente ao judaísmo no auto-de-fé de 8 de novembro de 1589 , tinham como propósito documentar a estória da perseguição dos adeptos da lei de Moisés no vice reinado da Nova Espanha. Narradas quase em sua totalidade na terceira pessoa do singular, através do protagonista Joseph Lumbroso, as "Memórias" terminam, porém, curiosamente, na primeira pessoa do singular. Como se pode observar através da passagem que segue, da descrição da planejada partida de Joseph Lumbroso e de sua família do reinado da Nova Espanha, a voz do narrador onisciente se converge na do protagonista, levando o leitor a identificar a estória de Joseph Lumbroso com a do próprio escritor (Luis de Carvajal):

y como por agora por estar el que esto ha escrito todavía en tierras de captiverio, aunque en vísperas de salir con la ayuda y favor del altísimo y fuertísimo, A. D. de Ysrael ... Por lo qual humillo mi corazón. Adoro y glorifico a su santísimo nome y confieso que es bueno y máximo y que es eterna su misericordia la qual no valga y a todo Ysrael amén (Procesos, 495-496).

Interpretando as "Memórias" segundo Paul De $\operatorname{Man}^{10}$ que sugere que a noção da referencialide biográfica depende mais da imaginação do que da realidade, é possível argumentar que essa obra de Carvajal consiste numa narrativa onde a retórica é mais

${ }^{9}$ Procesos de Luis de Carvajal (El Mozo) (México: Publicaciones del Archivo de la Nación, 1935) 504.

${ }^{10}$ Paul de Man, “Autobiography as De-facement”, Modern Language Notes 94 (December 1979) 919-930. 
importante do que a veracidade dos fatos relatados pelo narrador. Os fatos narrados por Carvajal nessa obra de caráter biográfico passam pelo crivo da imaginação de um escritor que buscava isentar de suas "Memórias" a sua experiência cristã. Dessa forma, como confissão autobiográfica ficcionalizada, as "Memórias" funcionam como uma catarse que permite com que Carvajal, como narrador onisciente, se desfaça de sua identidade cristãnova e se transforme, por meio da escrita, na pessoa/personagem judia Joseph Lumbroso.

Comparada com as "Memórias" de Carvajal, a Prosopopéia de Bento Teixeira, poema composto de noventa e quatro estrofes e dedicado ao governador de Pernambuco, também pode ser interpretado como uma catarse onde o poeta, ao criar sua obra a partir do relembrar dos seus sofrimentos passados e de sua experiência como cristão-novo, se sublima e se ficcionaliza, transformando-se no herói de sua Prosopopéia. Portanto, faz sentido buscar De Man para interpretar o poema épico do letrado cristão-novo da colônia luso-espanhola da América. Ao remontar à origem etimológica do termo prosopopéia, "prosopon paien," que se associa com "máscara" ou "face," De Man, conclui que por excelência a "prosopopéia é o tropo de autobiografia." (926).

No poema Prosopopéia, seguindo a tradição clássica renascentista, Bento Teixeira apresenta, além de uma dedicatória, uma "proposição", uma "invocação", uma narração e um epílogo. Expressões metafóricas encontradas no "Prólogo", tais como "obstardo pinzel de meu engenho" (15) e na invocação, "Verso ... tosco e rudo" (19), "Musa inculta e mal limada" (21), em contraste com os adjetivos "sincero" e "profundo" usados para se referir ao conteúdo da obra, parecem enfatizar a superioridade da mensagem ou do fundo, com relação à forma. Reconhecendo a limitação de seu talento artístico o poeta trata de dirigir a atenção do leitor para o conteúdo ou mensagem da poesia, destacando a presença de Deus supremo e único na "invocação" do poema:
Aquele chamo só, de quem espero
A vida que se espera em fim de tudo.
Ele fará meu Verso tão sincero,
Quanto fôra sem ele tosco e rudo. ${ }^{11}$

Conforme foi observado anteriormente, ao invocar a ajuda do sobrenatural para a criação do seu poema, Bento Teixeira seguiu o modelo literário da época. No entanto, ao se levar em conta a experiência do poeta, como cristão-novo, acusado de esposar o judaísmo, poder-se-ia interpretar os versos acima como uma manifestação da crença monoteísta do cripto-judeu. Na "narração", parte mais extensa do poema, existem vários elementos que poderiam servir como indicativos da mensagem judaica do poeta. Por exemplo, nos versos da estrofe XXIV do "Canto de Proteu," disfarçado na figura ambígua de Proteu, o poeta envia sua mensagem clamando por justiça e não por fama:

Porque dado que a forma se me muda,

Em falar a verdade serei raso,

Que assim convém fazê-lo quem escreve,

${ }^{11}$ Bento Teixeira, Prosopopéia. (Rio de Janeiro: Instituto Nacional do Livro/MEC, 1972) 19. 
Se à justiça quer dar o que se deve (35).

A figura camaleônica de Proteu poderia encontrar correspondência tanto na representação alegórica do poeta quanto na do cripto-judeu. Tal como Proteu, manipulador da forma, o poeta utiliza-se de seu talento artístico para moldar a linguagem e dar às palavras significados diferentes. Vista dessa maneira, a associação do poeta com Proteu encontra eco em David Quint, que afirma que Virgílio assigna a Proteu o título de vate, termo que combina as categorias de vidente e de poeta. Ainda segundo esse crítico, as transformações de Proteu podem ser entendidas como as palavras e as figuras da linguagem poética. ${ }^{12}$ A ambivalência do deus marinho que se utilizava do dom da profecia e da metamorfose para esquivar-se das perguntas dos indagadores, coincide também com a ambiguidade do cripto-judeu, que, para escapar dos inquisidores, dissimulava sua crença judaica através da aparência de cristão.

Metamorfoseado em Proteu e agindo como Moisés, que livrou do cativeiro e da opressão faraônica os israelitas ao abrir caminho nas pesadas águas do Mar Vermelho para apontar-lhes a Terra Prometida, o converso letrado, poeta-pastor, que na metrópole e na colônia fora depositário da confiança dos descendentes de Moisés, poderia estar se utilizando da escrita do seu poema para enviar mensagens aos cristãos-novos perseguidos pela política filipina e para apontar-lhes, na direção aos mares do sul, a área geográfica de Nova Lusitânia, conhecida por Pernambuco, como o locus ameno onde poderiam se unir e se proteger contra os seus perseguidores:

Para a parte do Sul, onde a pequena
Ursa se vê de guardas rodeada,
Onde o Ceo luminoso mais serena
Tem sua influição, e temperança;
Junto da Nova Lusitania ordena
A natureza, mãe bem atentada,
Um porto tão quieto e tão seguro,
Que para as curvas Naus serve de Muro (31).

A cidade do Recife, capital da região da Nova Lusitânia, transforma-se no poema numa espécie de Canaã tropical, "porto seguro" ou locus ameno, onde os cristãos-novos portugueses poderiam encontrar prosperidade e se resguardarem contra as perseguições do rei espanhol e dos inquisidores. ${ }^{13}$

\footnotetext{
${ }^{12}$ David Quint, Origins and Originality in Renaissance Literature (New Haven and London: Yale University Press, 1983). "Virgil assigns to Proteus the title of vates ... which combines the categories of seer and poet. His transformations can be undestood as the words and figures of poetic language". E, mais adiante: "Proteus, ... capable of an infinite variety of shapes, embodies the principle of difference itself"(38).

${ }^{13} \mathrm{O}$ argumento de que Bento Teixeira estivesse enviando uma mensagem aos seus confrades cristãosnovos se solidifica ao se atentar para o fato histórico de que a partir de 1629 Pernambuco foi invadido pelos holandeses e a cidade do Recife passou a ser uma espécie de locus ameno para os cristãos-
} 
Comparada com a de Bento Teixeira a crítica de Luis de Carvajal contra o imperador espanhol se manifesta de forma clara e acirrada, como se pode observar através do seguinte comentário que o letrado da Nova Espanha escreve no seu "Testamento": "creo que aquel rey Antioco, a quien la Sagrada Escritura llama raíz de pecado, por ser perseguidor del pueblo de Dios y de su Santa Ley, y fue figura de los reyes de España y Portugal, los cuales han sido y son la raíz de que han procedido y proceden los ramos de las inquisiciones" (416).

O fato de que a oficialização do Tribunal do Santo Ofício e das "visitaçães" no Novo Mundo tenha ocorrido durante o reinado de Filipe II sugere que Luis de Carvajal estava criticando o monarca espanhol. Uma vez que milhares de cristãos-novos e judeus foram perseguidos e condenados à morte durante o reinado do segundo herdeiro dos Habsburgo da Espanha, é coerente pensar que Carvajal estivesse se referindo ao rei espanhol no seu documento testimonial. Ao se referir aos reis "de España y Portugal" através do verbo ser no presente do indicativo, Carvajal, implicitamente, compara o imperador da Espanha e de Portugal com Antioco IV, rei assírio que na era pré-cristã escravizou os israelitas, forçandoos a substituir o altar de Jeová pelo de Zeus, tentando, assim, proibi-los de serem judeus.

Para concluir é relevante observar que apesar do recente interesse demonstrado pelos críticos em resgatar vozes marginalizadas pelo cânon, a produção dos letrados coloniais de origem judia, até o presente momento não logrou o merecido espaço nas páginas da crítica literária latino-americana. O corpus constituído pelos discursos confessional e literário do letrado cripto-judeu ou converso ainda representa um elo perdido, ou missing link, cujo valor histórico-cultural ultrapassa as fronteiras nacionais dos atuais países latino-americanos e cuja relevância como documentos para transmitir comentários sócio-políticos se aplicam tanto ao passado colonial, quanto ao presente.

Devido à ênfase dada ao aspecto estético, as exegeses da produção literária de sujeitos coloniais descendentes de hebreus deixam de abordar aspectos sociais e históricos que apontam para a experiência do cripto-judeu letrado.

No caso específico de Bento Teixeira, com exceção dos estudos realizados por Sônia Aparecida Siqueira, Luiz Roberto Alves e por Nelson H. Vieira, ${ }^{14}$ a crítica apenas tem focalizado os aspectos estéticos e formais da obra. Como resultado desse enfoque crítico parcial e míope, o poema épico teixeiriano entrou para a literatura portuguesa e brasileira, mas pela porta dos fundos. Vista como obra menor, a Prosopopéia ocupa espaço marginal nas páginas das antologias e dos volumes de crítica literária, como poemeto "sem mérito de inspiração, poesia ou forma", obrinha cheia de "arremedos dOs Lusiadas" (José

novos e judeus portugueses. Em sua obra The Records of the Earliest Jewish Community in the New World (New York: American Jewish Historical Society, 1959), Arnold Wiznitzer documenta que a congregação sefardita Zur Israel do Recife, a primeira das Américas, foi uma das mais progressitas da época, por reconhecer a igualdade de direito de seus membros e por não dividi-los em classe alta e baixa, como se fez na Holanda e, mais tarde, em Londres. Em suas palavras: "Here all Jews were considered citizens of the Jewish community, enjoying equal rights" (11).

${ }^{14}$ Sônia Aparecida Siqueira, "O cristão-novo Bento Teixeira: cripto-judaísmo no Brasil Colônia", Revista de História 90 (1972) 395-476; Luiz Roberto Alves, Confissão, poesia e Inquisição (São Paulo: Ática, 1983) e Nelson H. Vieira, "Simulation and Dissimulation: An Expression of CryptoJudaism in the Literature of Colonial Brazil", Colonial Latin American Review II (1993) 143-164. 
Veríssimo, História 27). Por focalizarem apenas o ângulo estético e formal da obra, os críticos literários, de maneira geral, deixaram de incluir em suas exegeses a dimensão social da Prosopopéia como obra chave para a penetração na complexidade do letrado cristão-novo na sociedade colonial de finais do século XVI.

No caso de Luis de Carvajal a situação é ainda pior do que a de Bento Teixeira. Com exceção de alguns poucos versos, os escritos de Luis de Carvajal, tão ricos na descrição dos conflitos entre espanhóis e índios, das dificuldades enfrentadas pelos desbravadores das inóspitas fronteiras nordestinas da Nova Espanha, do cotidiano dos colonizadores e colonizados e das pressões vividas pelos cripto-judeus, ainda não fazem parte do cânon. Em sua obra Poetas novohispanos, Alfonso Méndez Plancarte, sem mencionar Luis de Carvajal, inclui alguns versos do poeta cripto-judeu, mas acompanhados de um julgamento negativo, como se pode deduzir do seguinte comentário feito na introdução de sua antologia: "A la misma se acercan, aunque que de inferior calidad, unas Octavas que todavía como del XVI publicó ... Jesús García Gutiérrez y que los procesos contra Judaizantes que las conservan ..." As poesias de Carvajal que se encontram na obra La poesia religiosa en México: Siglos XVI a XLX de Jesús García Gutiérrez também aparecem como anônimas e desprovidas de qualquer comentário crítico.

Com respeito ao campo da história, os estudos sobre o converso ou cristão-novo, como sujeito colonial, a meu ver, pecam em dois sentidos. Primeiro porque tratam de delimitá-lo a contextos que, durante a época colonial não se encontravam divididos em realidades geo-políticas ou nações tais como as de hoje em dia. Segundo porque, ao delimitá-lo geograficamente, deixam de abordá-lo como sujeito transnacional, cuja preocupação se voltava mais para a sobrevivência individual e grupal do que para com os interesses ou fronteiras dos impérios ou colônias onde viviam. ${ }^{15}$

No que diz respeito ao caso específico do cripto-judeu letrado, por não considerarem as características estéticas, a linguagem, a polifonia de vozes e outros aspectos intrínsecos do texto literário, os historiadores deixam de enriquecer suas exegeses com exemplos textuais que poderiam ser interpretados como uma possível resposta do cripto-judeu, como sujeito colonial, pressionado por barreiras religiosas e econômico-sociais.

Com base nas observações acima, pode-se afirmar que apenas a análise cultural e multidisciplinar, que leve em conta tanto as produções literárias quanto os processos inquisitoriais dos cripto-judeus letrados, que no Novo Mundo marcaram presença crítica, poderá vir a ampliar o cânon e enriquecê-lo com novas perspectivas para a intrepretação da realidade colonial latino-americana.

\footnotetext{
${ }^{15}$ A minha interpretação difere, portanto, da que expressam Antonio Candido e e José Aderaldo Castello, quando afirmam no volume I da Presença da literatura brasileira (São Paulo: Difusão Européia do Livro, 1974) ter sido Bento Teixeira "o iniciador de uma tradição brasileira de nativismo grandiloquente" (29). Sílvio Romero, “A literatura 1500-1900”. Ed. Livro do Centenário., I (Rio de Janeiro: Imprensa Nacional, 1900) também vê Bento Teixeira como um precursor do nacionalismo brasileiro, ao afirmar que a Prosopopéia é "a primeira afirmação do nacionalismo que nunca mais a arte pátria havia deabandonar" (18-19).
} 
